Int. J. Electrochem. Sci., 15 (2020) 1108 - 1116

\title{
Dy-doped CoNi Alloy Films Prepared by Electroplating Method
}

\author{
Yundan Yu*, Guoying Wei, Li Jiang, Hongliang Ge \\ College of Materials Science and Engineering, China Jiliang University, Hang Zhou 310018, China \\ *E-mail: yuyundan@cjlu.edu.cn
}

doi: $10.20964 / 2020.02 .20$

Received: 16 September 2019 / Accepted: 12 November 2019 / Published: 31 December 2019

\begin{abstract}
Dysprosium sulfate was added into the electrolyte to prepare CoNi ally films by plating technology. The effect of dysprosium doping on electrochemistry process, composition, microstructure and corrosion resistance of $\mathrm{CoNi}$ was investigated. It was considered that $\mathrm{CoNi}$ alloy films electrodeposition was a kind of anomalous codeposition process. The percentage of cobalt content in CoNi films was higher than that of in the electrolyte. Higher concentration of dysprosium sulfate tended to decrease the cathodic polarization of CoNi electrodeposition resulting in the increase of deposition rate. The cobalt ions discharge was mainly affect by mass diffusion control. The rare earth dysprosium adsorbed on the cathode surface greatly affected the discharge process of cobalt ions to extremely decrease the content of cobalt in the CoNi alloy films. With the increase of dysprosium sulfate concentration in the electrolyte, the diffraction peak intensities of CoNi and cobalt decreased gradually while the surface morphology of CoNi alloy films changed from needle-like to nodular structure. Moreover, CoNi alloy films obtained in the electrolyte with higher dysprosium sulfate concentration possessed smaller grain size and condense surface morphology that contributed directly to the improvement of anticorrosion performance.
\end{abstract}

Keywords: CoNi alloy films; dysprosium doping; anticorrosion performance

\section{FULL TEXT}

(C) 2020 The Authors. Published by ESG (www.electrochemsci.org). This article is an open access article distributed under the terms and conditions of the Creative Commons Attribution license (http://creativecommons.org/licenses/by/4.0/). 